\title{
Experimental measurements of charge separation under wet growth conditions
}

\author{
M.Y. Luque*, R.E. Bürgesser, E.E. Ávila
}

Atmospheric Physic Group, FaMAF, Universidad Nacional de Cordoba, IFEG-CONICET, Córdoba, Argentina

*Correspondence to: M.Y. Luque, FaMAF, Av. Medina Allende s/n, Ciudad Universitaria, CP:X5000HUA Córdoba, Argentina. E-mail: mluque@famaf.unc.edu.ar

\begin{abstract}
In this work we present the results of experimental measurements of the charge transferred to simulated graupel under wet growth conditions. The range of temperature was between $7^{\circ} \mathrm{C}$ and ${ }^{-} 18^{\circ} \mathrm{C}$. The speeds of collision employed in the measurements were between 8 and $13 m s^{-1}$ with the goal of representing graupel of different initial densities. The aim of this study was to corroborate the existence of charge transfer under wet growth. The results show the presence of positive charge when graupel reaches partial wet growth, and the magnitude of this charge is comparable to the charge transferred under dry growth conditions. On the other hand, when total wet growth is reached no charge transfer is registered. This leads to the conclusion that the non-inductive mechanism could be working under partial wet growth conditions when the ice crystals collide with the dry regions of the graupel surface and then bounce off.
\end{abstract}

\section{Key Words}

This article has been accepted for publication and undergone full peer review but has not been through the copyediting, typesetting, pagination and proofreading process, which may lead to differences between this version and the Version of Record. Please cite this article as doi: 10.1002/qj.3259 
Wet growth, Cloud Electrification, Ice crystal-graupel interaction, Charge Transfer.

\section{Introduction}

Previous experimental studies have shown that the main electrification process in thunderstorm is the non-inductive mechanism which proposes that electrical charge is separated during collisions between graupel and ice crystals under different cloud conditions (Reynolds et al., 1957; Takahashi, 1978; Jayaratne et al., 1983; Saunders et al., 1991, 1999, 2001, 2004, 2006; Brooks et al., 1997; Saunders and Peck, 1998; Ávila and Pereyra, 2000; Pereyra et al., 2000, 2008; Pereyra and Ávila, 2002; Bürgesser et al., 2006;

Lighezzolo et al., 2010; Ávila et al., 2013; Luque et al., 2016). From these studies it has been concluded that the non-inductive mechanism is sensitive to the cloud microphysical conditions. It is well known that the magnitude and the sign of the charge transfer to the graupel depend on several environmental parameters such as cloud temperature, liquid water content, cloud droplet and ice crystal sizes, relative humidity and impact velocity.

The non-inductive electrification mechanism is based on the collision between ice crystals and graupel and the subsequent separation of the interacting ice particles. During the brief contact, mass is exchanged between the ice particles and, as consequence of that, electrical charge is separated (Latham, 1981; Mason and Dash, 2000). Therefore, this mechanism will be able to separate charge only if the ice crystals bounce off the graupel surface without sticking. The probability of an ice crystal sticking to the graupel surface depends on the temperature, the surface area, and the kinetic collision energy of the impacting particles. Under wet growth conditions of the graupel, a layer of liquid water 
forms over the graupel surface increasing the sticking efficiency which affects the performance of the non-inductive mechanism.

Some experimental studies have reported no charge separation during wet growth (Saunders et al., 1991; Saunders and Brooks, 1992). However, Takahashi (1978) reported a strong positive charge acquired by the graupel at high liquid water content and at high temperatures. Williams et al. (1991) and Jayaratne (1993), using the heat balance equation (Macklin and Payne, 1967), concluded that the measurements of Takahashi were carried out with the graupel under wet growth conditions. Based on these results, Williams et al. (1991) suggested that ice crystals could bounce off a hailstone under wet growth conditions charging it positively.

Recently, Jayaratne and Saunders (2016) reported a significant positive charge transfer when ice crystals interacted with a simulated hailstone in wet growth. On this study, the magnitude of the charge transferred to the simulated hailstone when ice crystals collided against it, under wet growth conditions, was experimentally measured. The hailstone was simulated by a stainless steel rod of $32 \mathrm{~mm}$ length and $4 \mathrm{~mm}$ diameter. The experiments were carried out at an ambient temperature of $-10^{\circ} \mathrm{C}$ and at two different speeds collision: $12 \mathrm{~m} \mathrm{~s}^{-1}$ and $20 \mathrm{~m} \mathrm{~s}^{-1}$. They reported a charge transferred per ice crystal of $20 \mathrm{fC}$ at $12 \mathrm{~m} \mathrm{~s}^{-1}$ and $50 \mathrm{fC}$ at $20 \mathrm{~m} \mathrm{~s}^{-1}$, assuming that 1 of 100 ice crystals rebounded off the hailstone surface. They suggested that some regions of the hailstone surface remained dry even under wet growth conditions and that in those regions the non-inductive mechanism could work thus explaining the charge acquired by the hailstone.

Based on the experimental evidence that under wet growth the graupel acquires a positive charge, the main goals of this work are to study the performance of the noninductive mechanism under wet growth conditions, extending the conditions studied by 
Jayaratne and Saunders (2016), and to corroborate the suggestion that the charge separated is due to the interaction of ice crystals with dry zones of the graupel surface.

\section{Experiments}

\subsection{Experimental Setup}

The measurements were carried out using the experimental setup showed in Figure 1. The main components of the experimental device are: the Ice Crystals Chamber (ICC), the Cloud Chamber $(\mathrm{ClC})$, the wind tunnel and the target. The experimental device was placed inside a Cold Chamber with controlled temperature capable of reaching temperatures down to $-30^{\circ} \mathrm{C}$.

The ICC, where the ice crystal cloud was generated, consists of a metallic box with dimensions $1.8 \mathrm{~m}$ height and $0.6 \mathrm{x} 0.9 \mathrm{~m}^{2}$ base. The $\mathrm{ClC}$, where the cloud of supercooled water droplets was generated, consists of a metallic box of $60 \mathrm{~cm}$ with a showerhead placed inside. The supply of water for the showerhead was contained on a reservoir (R) placed outside the Cold Chamber (Figure 1). The ClC and the ICC were connected by a wind tunnel to an air pump capable of enabling and disabling the airflow into the tunnel and regulating its speed.

The target consists of a brass sphere of $1 \mathrm{~cm}$ diameter which simulates a graupel. It was placed inside the wind tunnel as can be observed in Figure 1. The target was connected to a current amplifier with 1pA precision. The current sensed by the amplifier is a measure of the charge acquired by the target during its interaction with the ice crystals in presence of the supercooled droplets. 
Adjusting the power of the air pump, the speed of the airflow was controlled. The measurements were carried out at three different ranges of speeds: $8 \mathrm{~m} \mathrm{~s}^{-1}$ to $10 \mathrm{~m} \mathrm{~s}^{-1}, 10 \mathrm{~m} \mathrm{~s}^{-1}$ to $12 \mathrm{~m} \mathrm{~s}^{-1}$, and $12 \mathrm{~m} \mathrm{~s}^{-1}$ to $13.5 \mathrm{~m} \mathrm{~s}^{-1}$. Different collision speeds were selected to represent graupel of different initial densities. The lower speeds represent a graupel with an initial density of $0.5 \mathrm{~g} \mathrm{~cm}^{-3}$; the medium speeds correspond to an initial graupel density of $0.7 \mathrm{~g}$ $\mathrm{cm}^{-3}$ and the higher speeds represent graupel with an initial density of $0.9 \mathrm{~g} \mathrm{~cm}^{-3}$. These densities are in concordance with real graupel densities which vary according to its growth conditions (Heymsfield and Kajikawa, 1987).

Three temperatures were recorded during the experiment: the ICC temperature ( $\mathrm{T}_{\mathrm{ICC}}$ ), the wind tunnel temperature $\left(\mathrm{T}_{\mathrm{WT}}\right)$ and the target temperature $\left(\mathrm{T}_{\mathrm{T}}\right)$. These values were sensed using three previously calibrated thermistors. The location of the thermistors can be seen in Figure 1.

To generate the ice crystal cloud inside the ICC, a nebulizer is used to introduce a supercooled cloud of distilled water droplets. Ice crystal nucleation is achieved by cooling a local volume of the droplet cloud when a rapid expansion of compressed air contained inside a syringe is provoked. Finally, ice crystals grow at the expense of the water droplets until the ice crystal cloud is formed.

Samples of the ice crystals in the wind tunnel were taken at different temperatures. The process to obtain these samples consists of coating $8 \mathrm{~mm}$ wide glass plates with Formvar at 3\% and then inserting them into the slit inside the wind tunnel and holding them there for 5 seconds while air was passing at $13 \mathrm{~m} \mathrm{~s}^{-1}$. The Formvar technique is detailed in Schaefer (1956). The samples were taken around 90 seconds after seeding. Figure 2 shows the ice crystal sizes used in the experiments at different temperatures. The boxes represent the standard deviation, the line inside them represents the median value, the little squares 
represent the mean value and the small dashes represent the minimum and maximum values of the ice crystals. Mean size values of the ice crystals sampled were between $8 \mu \mathrm{m}$ and $22 \mu \mathrm{m}$ and median values varied between $5 \mu \mathrm{m}$ and $18 \mu \mathrm{m}$.

The supercooled droplet cloud inside the ClC was formed by vapour condensation of water molecules evaporated from the hot shower. The liquid water content during a measurement depends on the temperature difference between the water in the reservoir $\mathrm{R}$ and the surrounding air. The mean diameter of water droplets used in the experiments was around $8 \mu \mathrm{m}$. This value was obtained after analyzing Formvar samples from the droplet cloud. The procedure to obtain these samples is similar to that used to obtain the ice crystal samples.

\subsection{Experimental Procedures}

To perform the measurements of the charge transferred to the graupel during its interaction with ice crystals in the presence of supercooled droplets, the next steps were followed:

1. The cold chamber was set at the desired temperature.

2. The water in the reservoir was heated up to the desired temperature.

3. Distilled water droplets were introduced in the ICC with the nebulizer for about 3 minutes.

4. The ice crystals were nucleated and they grew by vapour deposition for about 60 s.

5. The water from the reservoir $\mathrm{R}$ was released to form the supercooled droplet cloud. Ten seconds later the air flow was initiated by turning on the pump. 
On average, measurements lasted 100 seconds. Secondary experiments were performed and they showed that ice crystals inside the ICC lasted for at least 300s assuring a nearly constant ice crystal concentration during the entire measurement and discarding the possibility of null CC as consequence of the absence of ice crystals.

\section{Experimental Results and Discussion}

Measurements of the charging current to the simulated graupel during ice-crystal collisions in the presence of supercooled droplets under wet growth conditions were carried out at temperatures between $-7^{\circ} \mathrm{C}$ and $-18^{\circ} \mathrm{C}$ at a range of impact speeds between $8 m \mathrm{~s}^{-1}$ and $13 \mathrm{~m} \mathrm{~s}^{-1}$.

Figure 3 shows the sign of the charge current to the graupel as a function of the ambient temperature and the rime accretion rate $\left(R_{A E}\right)$ under wet growth conditions. Open circles represent a positive charge acquired by the graupel while black circles represent conditions where the graupel charging current was zero. The $R A E$ combines the effect of the effective liquid water content $(\mathrm{EW})$ with the impact velocity $\left(E^{2} A R^{*}=E W \times V\right)$. From Figure 3 it can be observed that the sign of the nonzero charge current was always positive. In addition, some measurements of the graupel charge under conditions in which the air flow contained only supercooled droplets were performed. Under these conditions no appreciable current ( $>1 \mathrm{pA}$ ) was detected on the graupel. Therefore, it can be assumed that the graupel current registered was exclusively due to interactions between the ice crystals and the graupel. 
Although the graupel temperature was registered during the experiments, its value is not completely representative of the real temperature of the graupel surface during the entire measurement. The water droplets that impact and freeze on the graupel, increase the thickness of the ice layer and isolate the temperature sensor from the graupel surface. This causes the measured temperature to be lower than the actual one. Therefore, the EW values used in the experiments cannot be determined using the heat balance equation (Macklin and Payne, 1967), which relies on a knowledge of the rime surface temperature. Instead, the accreted mass on the target was completely removed and weighted after each measurement and EW was determined from these data. It is important to clarify that EW and RAR values determined from the accreted mass are mean values over the whole surface of the target. Because of airflow, the center of the target should have a higher RAR than closer to the equator. If the edges have a sufficiently lower RAR, that could also help explain the persistence of charging (e.g., lower RAR but fewer ice crystal hits).

The lines in Figure 3 represent theoretical curves at which the graupel reaches a temperature of $0^{\circ} \mathrm{C}$ (Solid line) and a temperature of $-5^{\circ} \mathrm{C}$ (Broken line). The $-5^{\circ} \mathrm{C}$ temperature is used as reference since there is evidence that wet growth is reached for graupel temperature below $0^{\circ} \mathrm{C}$ (List et al. 1989). These theoretical curves were derived using the heat balance equation (Macklin and Payne, 1967) for a spherical collector of diameter $1 \mathrm{~cm}$. Therefore, values of $R A A$ and ambient temperature above the theoretical curves should indicate conditions of wet growth of the graupel.

From Figure 3, it can be observed that almost all measurements were performed under wet growth conditions, according to the theoretical curves, and zero current to the graupel under such conditions was expected (Saunders et al., 1991; Saunders and Brooks, 
1992). However, most of the measurements showed a positive current to the graupel during ice crystal interactions. These results are in agreement with the results reported by Takahashi (1978) and Jayaratne and Saunders (2016) who also found a positive charge transfer to the graupel under wet growth conditions.

Experimental and theoretical studies (List et al., 1989; Nasello et al., 1992) have shown that the mean surface temperature of an accreting graupel is not enough to describe the superficial conditions of the graupel. Therefore, given that theoretical curves showed on Figure 3 are based on the mean temperature over the graupel surface, the information that they provide, seems to be inadequate as an indicator of wet growth conditions over the entire graupel surface.

List et al. (1989) carried out experiments where they determined the temperature of the equator (stagnation point) and pole ( $90^{\circ}$ from stagnation point) of a rotating spherical graupel growing by accretion. In those experiments, the graupel was inside a wind tunnel at an ambient temperature of $-15^{\circ} \mathrm{C}$. The measurements were carried out for different values of liquid water content with a wind speed of $19.8 \mathrm{~m} \mathrm{~s}^{-1}$. They found that when graupel reached wet growth, the surface graupel temperature was always below $0^{\circ} \mathrm{C}$. They also discovered a considerable difference between the surface temperatures at the equator and pole, which depended on the liquid water content at the same values of wind speed and ambient temperature. They concluded that heat transfer needs to be treated as non homogeneous and non-isotropic and that the surface temperature of the graupel cannot be considered as one single value. In later experiments, List et al. (1995) determined the surface temperature variations of gyrating hailstones. They found that the growth by accretion of hailstones under certain cloud conditions was characterized by a dry and cold 
regime at the poles and a wet and warmer regime at the equator. From direct observations they associated dry regions with opaque ice and wet regions with transparent ice.

Nasello et al. (1992) did a theoretical study which showed that there was a surface temperature distribution for ice accreted on a cylindrical collector which had a maximum value on the stagnation point and decreased to the sides. They arrived at these results after considering that it was necessary to include in the equations of heat exchange the factors that take into account the thermal conductivity of the entire graupel.

Therefore, in order to identify the graupel surface conditions during the experiments, visual examinations of the graupel surface were realized after each measurement. From the examinations of the graupel surface, it was possible to relate the measurements with zero charging current with the observations of totally transparent graupel, which indicates that the entire graupel surface was wet. On the other hand, the measurements with non-zero current were coincident with observations of a graupel surface with both transparent and opaque areas. The transparent areas indicate a wet growth regime while the opaque areas indicate dry growth conditions. So, it may be possible that ice crystals collide with these areas under dry growth conditions and bounce off allowing the non-inductive mechanism to operate, as was suggested by Jayaratne and Saunders (2016). In general, it was observed that the accretion thickness around the stagnation point was thicker than the thickness closer to the equator. Assuming that the air speed around the sphere is approximately constant, it expected that the edges have lower local RAR than the top of the target. These could be the regions where the charging mechanism is working on.

The visual examinations of the graupel surface have shown that theoretical curves are not enough to determine the growth conditions of the entire graupel surface, as was 
reported by List et al. (1989) and Nasello et al. (1992). Reaching partial or total wet growth seems to depend on the liquid water content, collision speed and ambient temperature. As can be observed from Figure 3, total wet growth is reached mostly at ambient temperatures higher than $-10^{\circ} \mathrm{C}$ while at lower temperatures the environmental conditions used in the experiments are not enough to achieve this growth condition.

Figure 4 shows the charge current (CC, Upper panel) and the temperature of the target $\left(\mathrm{T}_{\mathrm{T}}\right.$, Lower panel) as functions of time for a measurement where partial wet growth was reached. The measurement corresponds to an ambient temperature of $-13.5^{\circ} \mathrm{C}$, a collision speed of $13 \mathrm{~m} \mathrm{~s}^{-1}$ and an $\mathrm{EW}$ of $2.13 \mathrm{gm}^{-3}$. During the first 10 seconds of the measurement, CC is zero since there was no air flow in the wind tunnel and therefore, there were no ice crystals interacting with the target. At 10 seconds, the air pump was turned on. The negative peak between 10 and 20 seconds corresponds to charge transfer due to collisions between ice crystals and the metallic surface of the target which is not covered by ice at the beginning of each measurement. Then, the accretion process initiates and the target temperature begins to increase due to the latent heat released as a consequence of the freezing of the water droplets that impact on it. A maximum positive CC of around 10pA is observed. At 60 seconds, the target temperature reaches a stationary value of $-3.5^{\circ} \mathrm{C}$ and by then the CC has decreased to 5pA. This CC value remains constant until the end of the measurement when the air pump is turned off at 80 seconds. CC between 20 and 50 seconds corresponds to interactions under dry growth conditions of the graupel while CC between 50 and 80 seconds corresponds to interactions under partial wet growth conditions of the graupel. As can be observed, the magnitude of CC during both growth conditions have the same order of magnitude, indicating that the charge acquired by the graupel under partial wet growth condition could be relevant to the electrification mechanism. 
An estimation of the charge transferred to the graupel per collision of individual ice crystals can be performed using the magnitude of the CC and the ice crystal concentration $(N)$. As was derived by Luque et al. (2016), the average charge transferred to the graupel per individual collision can be estimated from,

$$
q=\frac{C C}{p\left(E_{c} N\right) V A}
$$

where $A$ is the cross-sectional area of the target and $V$ is the collision speed. $E_{c}$ is the average collision efficiency of the target for ice crystals, which is defined as the ratio between the number of ice crystals that collide with the collector and the number of ice crystals within its path and $p$ is the probability that an ice crystal collides with the target and bounces off. The value of $\left(E_{c} N\right)$ is the number of ice crystals, per unit of volume that hit the target. From the Formvar samples, the value of $\left(E_{c} N\right)$ was estimated as $(3 \pm 2)$ ice crystals per $\mathrm{cm}^{3}$ assuming that the target and the glass strip, used as sampler, have the same collision efficiency. Given that the magnitude of CC under wet growth conditions varied between $1 \mathrm{pA}$ and $6 \mathrm{pA}$, the charge transferred per collision also varied between 1 and $3 \mathrm{fC}$ if we assume a value of $p$ of unity (all the ice crystals that collide with the target, rebound). However, under wet growth, a percentage of the ice crystals that collide, remain stuck to the graupel. If we suppose that only $10 \%$ of ice crystals collide and rebound from the graupel $(p=0.1)$ then, the charge transfer per collision will increase to 10fC and so on. These values of charge transferred are similar to those reported by Jayaratne and Saunders (2016) with a collision speed of $12 \mathrm{~m} \mathrm{~s}^{-1}$. Our values are also in agreement with those found by Takahashi (1978) in the wet growth region who reported a charge per collision of 30fC.

\section{Summary and conclusion}

This article is protected by copyright. All rights reserved. 
Novel experimental measurements of the charging current of a simulated graupel, under wet growth, during ice crystal interactions were performed. The measurements were realized at temperatures between $-7^{\circ} \mathrm{C}$ and $-18^{\circ} \mathrm{C}$ in a range of impact speeds from $8 \mathrm{~m} \mathrm{~s}^{-1}$ to $13 m s^{-1}$.

Visual observations of the graupel surface showed that the graupel presented some areas with dry growth and others with wet growth conditions. On the dry areas, ice crystals could impact without sticking and charge could be transferred between the interacting ice particles.

The results show that the graupel charging current during wet growth was always positive and had the same order of magnitude as the current during dry growth. Also, it can be estimated that mostly for warmer temperatures, if the EW value increased enough, the total wet growth would be reached eventually and, as consequence of this, the graupel charging current would be zero.

Finally, a charge transferred per collision of 10 to $30 \mathrm{fC}$ was estimated for a $p$ value of 0.1 , which is in concordance with previous values reported.

\section{Acknowledgements}

We thank Secretaría de Ciencia y Tecnología de la Universidad Nacional de Córdoba (UNC), Consejo Nacional de Investigaciones Científicas y Tecnológicas (CONICET) and Agencia Nacional de Promoción Científica (FONCYT) for financial support. We thank Rodolfo Pereyra and José Barcelona for their technical assistance. 


\section{References}

Ávila EE, Pereyra RG. 2000. Charge transfer during crystal-graupel collisions for two different cloud droplet size distributions. Geophys. Res. Lett. 27: 3837-3840.

Ávila EE, Lighezzolo RA, Castellano NE, Pereyra RG, Bürgesser RE. 2013. Laboratory measurements of charge separation in low liquid water content conditions and low impact velocity. J. Geophys. Res. Atmos. 118: 6680-6687.

Baker B, Baker M, Jayaratne E, Latham J, Saunders CPR. 1987. The influence of diffusional growth rate on the charge transfer accompanying rebounding collisions between ice crystals and hailstones. Q. J. R. Meteorol. Soc. 113: 1193-1215.

Bürgesser RE, Pereyra RG, Ávila EE. 2006. Charge separation in updraft of convective regions of thunderstorm. Geophys. Res. Lett. 33: L03808

Heymsfield AJ, Kajikawa M. 1987. An improved approach to calculating terminal velocities of plate-like crystals and graupel. Journal of the atmospheric sciences. 44: 10881099.

Jayaratne ER, Saunders CPR, Hallett J. 1983. Laboratory studies of the charging of soft hail during ice crystal interactions. Q. J. R. Meteorol. Soc. 109: 609-630. 
Jayaratne ER, Saunders CPR. 2016. The interaction of ice crystals with hailstones in wet growth and its possible role in thunderstorm electrification. Q. J. R. Meteorol. Soc. 142: $1809-1815$.

Latham J. 1981. The electrification of thunderstorms.Q.J.R. Meteorol. Soc.107: 277-298.

Lighezzolo RA, Pereyra RG, Ávila EE. 2010. Measurements of electric charge separated during the formation of rime by the accretion of supercooled water droplets. Atmos. Chem. Phys. 10: 1661-1669.

List R, Greenan BWJ, García-García F. 1995. Surface temperature variations of gyrating hailstones and effects of pressure-temperature coupling on growth.Atmospheric Research.38: 161-175.

List R, Garcia-Garcia F, Kuhn R, Greenan B. 1989. The supercooling of surface water skins of spherical and spheroidal hailstones. Atmospheric Research. 24: 83-87.

Luque MY, Bürgesser RE, Ávila EE. 2016. Thunderstorm graupel charging in the absence of supercooled water droplets. Q.J.R. Meteorol. Soc.142: 2418-2423.

Macklin WC and Payne GS. 1967. A theoretical study of the ice accretion process. Q. J. R. Meteorol. Soc. 93: 195-213. 
Mason BL and Dash JG. 2000. Charge and mass transfer in ice-ice collisions: Experimental observations of a mechanism in thunderstorm electrification. Journal of Geophysical Research: Atmospheres. 105(D8): 10185-10192.

Nasello OB, Castellano NE, Levi L. 1992. Surface temperature distribution for ice accreted on a cylindrical collector. Atmospheric research. 28: 153-171.

Pereyra RG, Ávila EE. 2002. Charge transfer measurements during single ice crystal collisions with a target growing by riming. J. Geophys. Res. 107: 4735.

Pereyra RG, Ávila EE, Castellano NE, Saunders CPR. 2000. A laboratory study of graupel charging. Atmos. Phys. 105: 20803-20812.

Pereyra RG, Bürgesser RE, Ávila EE. 2008. Charge separation in thunderstorm conditions. J. Geophys. Res. 113: D17203.

Reynolds SE, Brook M, Gourley MF. 1957. Thunderstorm charge separation. J. Meteorol. 14: 426-436.

Saunders CPR, Keith W, Mitzeva RP. 1991. The effect of liquid water on thunderstorm charging, J. Geophys. Res. 96: 11007-11017. 
Saunders CPR, Peck SL. 1998. Laboratory studies of the influence of the rime accretion rate on charge transfer during crystal/graupel collisions. J. Geophys. Res. 103: 1394913956.

Saunders CPR, Ávila EE, Peck SL, Castellano NE, Aguirre Varela GG. 1999. A laboratory study of the effects of rime ice accretion and heating on charge transfer during ice crystal/graupel collisions. Atmospheric Research. 51: 99-117.

Saunders CPR, Peck SL, Aguirre Varela GG, Ávila EE, Castellano NE. 2001. A laboratory study of the influence of the water vapor and mixing on the charge transfer process during collisions between ice crystals and graupel. Atmospheric Research. 58: 187-203.

Saunders CPR, Bax-Norman H, Ávila EE, Castellano NE. 2004. A laboratory study of the influence of ice crystal growth conditions on subsequent charge transfer in thunderstorm electrification. Q. J. R. Meteorol. Soc. 130: 1395-1406.

Saunders CPR, Bax-Norman H, Emersic C, Ávila EE, Castellano NE. 2006. Laboratory studies of the effect of cloud conditions on graupel/crystal charge transfer in thunderstorm electrification. Q. J. R. Meteorol. Soc. 132: 2655-2676.

Schaefer VJ. 1956. The preparation of snow crystal replicas - VI. Weatherwise. 9: 132135. 
Takahashi T.1978. Riming electrification as a charge generation mechanism in thunderstorms. J. Atmos. Sci. 35: 1536-1548.

Williams ER. 1989. The tripole structure of thunderstorms. J. Geophys. Res. 94: 1315113167.

\section{Captions}

Figure 1. Experimental Setup.

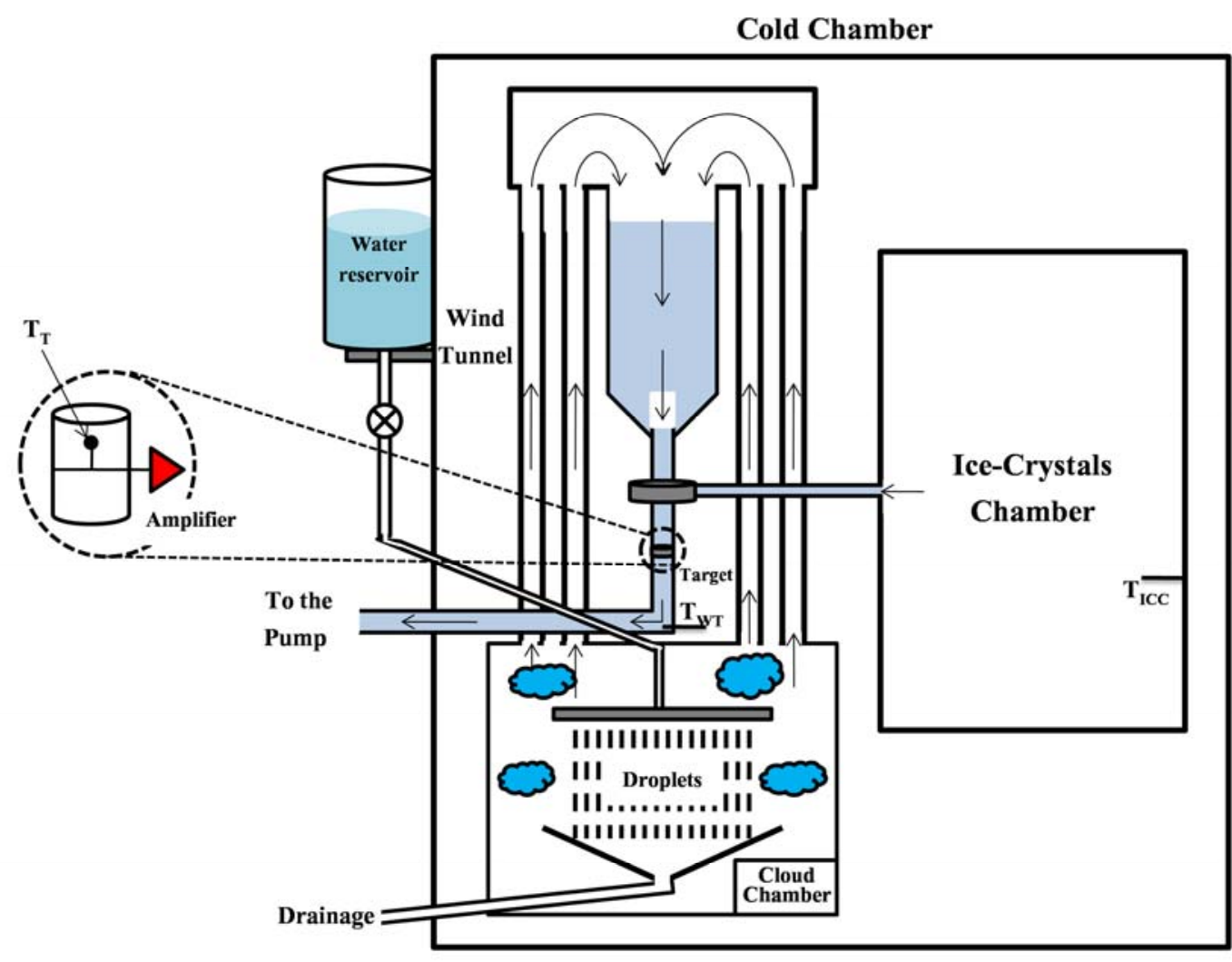

Figure 2. Statistical analyses as box charts for the ice crystals concentration. Squares and horizontal bars inside the boxes indicate the mean and median for ice crystal diameters respectively. The boxes indicate the standard deviation and the small dashes indicate the minimum and maximum ice crystal diameters. 


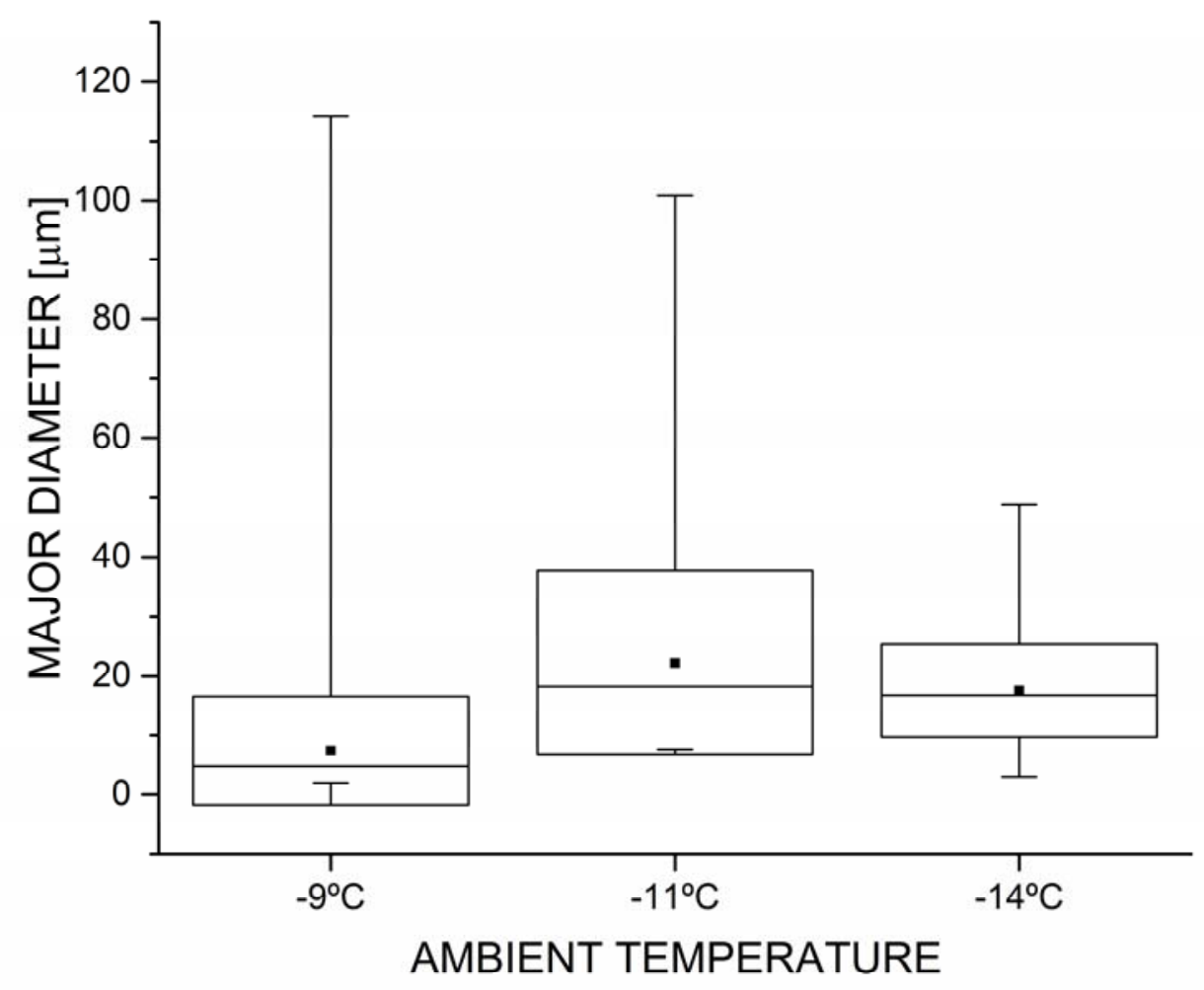

Figure 3. Sign of the charge current measured on the graupel as a function of the ambient temperature and the rime accretion rate (RAR) under wet growth conditions. Open circles represent a positive charge acquired by the graupel and black circles represent conditions where the charging current to the graupel is zero. Solid and broken lines represent theoretical limits for wet growth region when the graupel reaches $0^{\circ} \mathrm{C}$ and $-5^{\circ} \mathrm{C}$ respectively. 


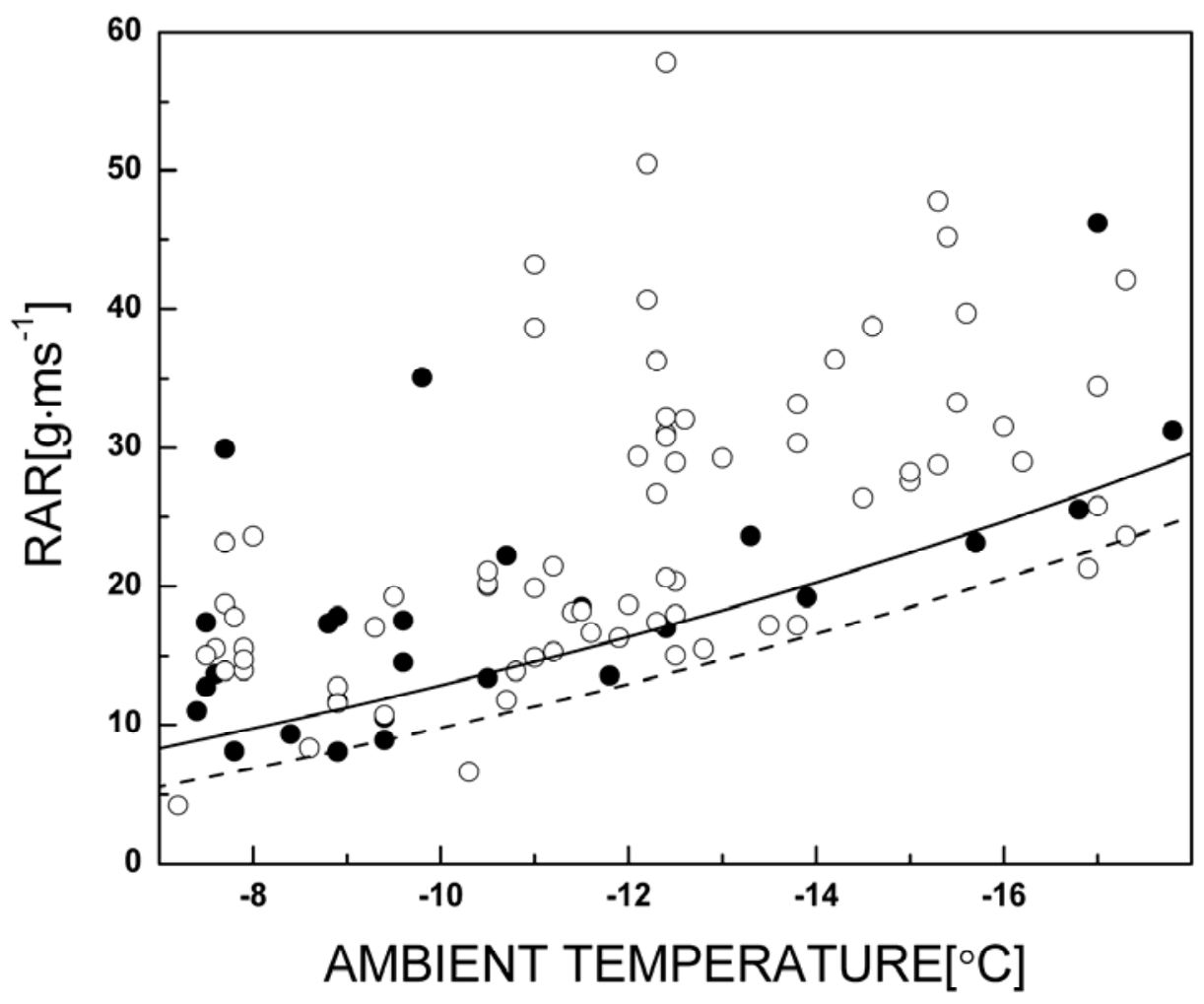

Figure 4. Temporal evolution of the CC (Upper panel) and of the graupel temperature (Lower panel). The measurement was carried out at $-13.5^{\circ} \mathrm{C}$ and at $13 \mathrm{~m} \mathrm{~s}^{-1}$, and partial wet growth was reached. 


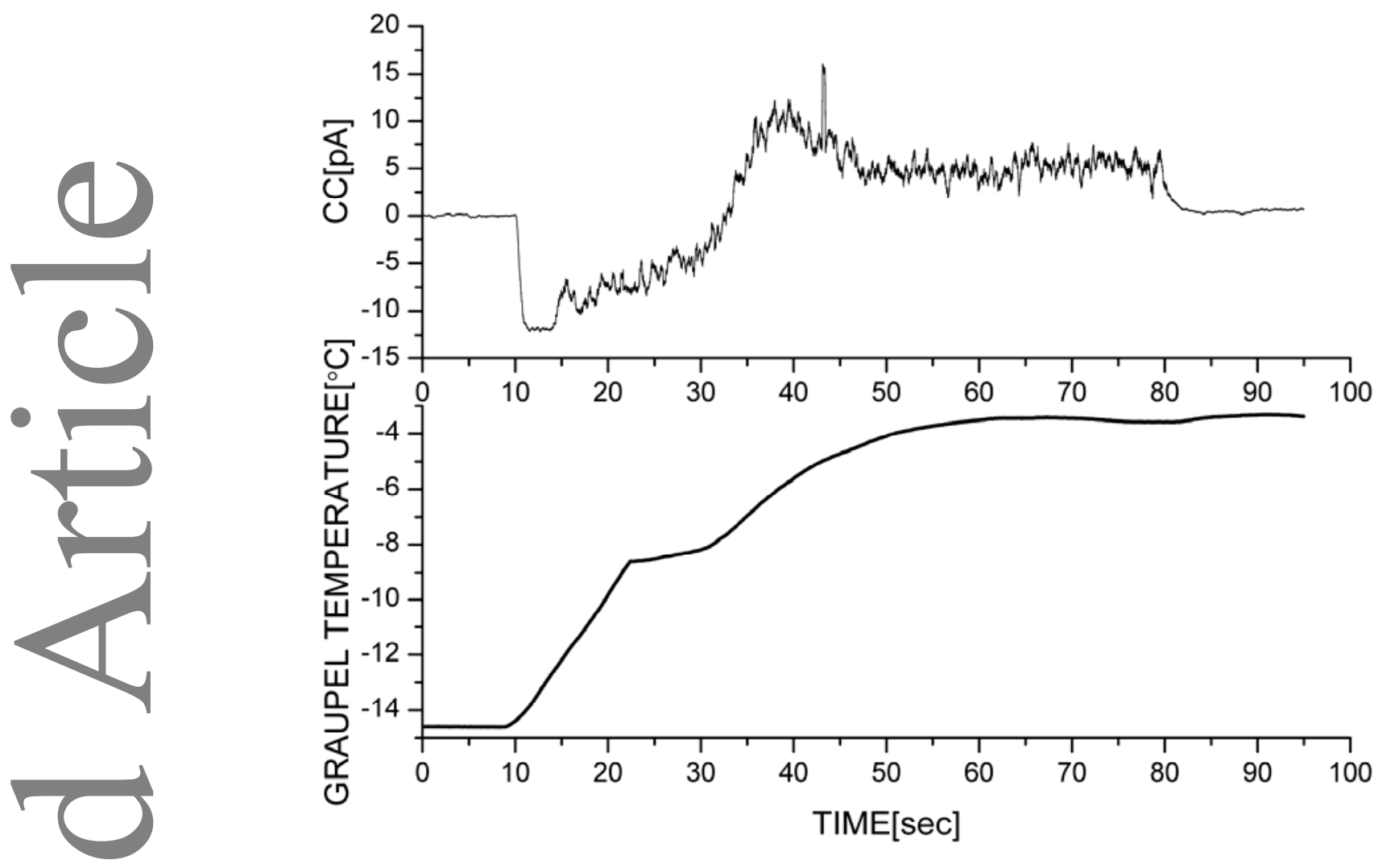

